\title{
O PAPEL DE FATORES FUNCIONAIS NA COMPATIBILIZAÇÃO SEMÂNTICA ENTRE VERBO E CONSTRUÇ̃̃O DE ESTRUTURA ARGUMENTAL PASSIVA EM PORTUGUÊS BRASILEIRO ${ }^{1}$

\author{
THE ROLE OF FUNCTIONAL FACTORS IN THE SEMANTIC \\ COMPATIBILIZATION BETWEEN VERB AND PASSIVE CONSTRUCTION IN \\ BRAZILIAN PORTUGUESE
}

\author{
Larissa Santos Ciríaco
}

\begin{abstract}
Resumo: Neste trabalho investiga-se a compatibilização entre verbo e construção de estrutura argumental passiva em português sob uma perspectiva construcionista (Goldberg, 1995, 2006). Especificamente, verifica-se o papel de dois aspectos funcionais relevantes para o significado da construção passiva, a saber: a Restrição de Afetação (Pinker et al, 1987) e a Função de Desfocalização do Agente (Shibatani, 1985, 2006). Conclui-se que esses fatores funcionais, em consonância com os modelos teóricos baseados no uso, atuam como restrições graduais e complementares na compatibilização: a passiva apresenta um cenário convencionalizado de ação que atua como uma condição coercitiva. Esse cenário convencionalizado licencia o uso de verbos que, do contrário, não se harmonizariam ao sentido da construção, sendo responsável por estender a cobertura da construção passiva na língua.
\end{abstract}

Palavras-chave: construção de estrutura argumental passiva; compatibilização semântica; fatores funcionais.

Abstract: This paper aims at investigating the role of functional factors in the semantic compatibility between verbs and the passive construction in Brazilian Portuguese. Specifically, we analyze the Affectedness Restriction (Pinker et al, 1987) and the Agent Defocusing Function (Shibatani, 1985, 2006), concluding that those aspects of meaning are gradual and complementary constraints. Besides that it is shown that the passive construction has a conventionalized scenario as an aspect of its meaning, which functions as a type of coercion mechanism. The conventionalized scenario licenses the compatibility of some verbs that, otherwise, would not be used in the passive, being responsible for extending the coverage of the construction.

Keywords: passive argument structure construction; semantic compatibility; functional factors.

\section{INTRODUÇÃO}

Investigar a compatibilização semântica entre verbos e construções de estrutura argumental é uma questão central para a determinação da natureza das representações que subjazem à capacidade linguística dos usuários de uma língua. Tradicionalmente, essas representações, especialmente no que tange à construção passiva, são tratadas como

\footnotetext{
${ }^{1}$ Este artigo é uma versão atualizada de parte de meu trabalho de tese de doutorado (CIRÍACO,2011), e foi desenvolvido com apoio financeiro do CNPQ - Edital Universal 2018.

${ }^{2}$ Universidade Federal de Minas Gerais (UFMG), Belo Horizonte, MG, Brasil.

Orcid: https://orcid.org/0000-0001-8009-6839

Agradeço aos dois pareceristas anônimos pelas observações e sugestões que contribuíram para a versão final deste artigo. Erros remanescentes são de minha inteira responsabilidade.
} 
puramente sintáticas (Chomsky, 1993, 1995), ou seja, como regras ou processos imunes ao contexto e à informação semântica. Outras abordagens enfatizam a função comunicativa e simbólica da linguagem (Pinker, 2013; Goldberg, 1995, 2006; Langacker, 1987, 1990, 1991, 2008; Perini, 2015, 2019; Tomasello, 2003 etc), mostrando que construções linguísticas refletem construtos cognitivos motivados pelo uso e, por isso, não podem ser tomadas como regras formais cegas ao significado. Uma evidência do papel de fatores semânticos e pragmáticos no funcionamento das construções é o fato de que nem toda construção ativa pode ser convertida em passiva (1) ou vice-versa (2):

(1) Bernardo tem um avião de lego. / *Um avião de lego é tido por Bernardo.

(2) Bernardo foi incompreendido pela professora. / *A professora incompreendeu Bernardo.

Além disso, embora a construção passiva seja muito produtiva, dada sua cobertura $^{3}$ extensiva a diversos tipos semânticos de verbos na língua, nem todo verbo se harmoniza com seu significado, como mostram (1) e os exemplos seguintes:

(3) A notícia me desanimou. / *Eu fui desanimada pela notícia.

(4) Esse jogo custou cem reais. / $*$ Cem reais foram custados por esse jogo.

Assim, almejando investigar o papel de fatores funcionais na compatibilização entre verbo e construção passiva, a pesquisa deste artigo se insere na corrente de estudos da Linguística Baseada no Uso (Usage-based Linguistics, cf. Barlow e Kemmer, 2000; Tomasello, 2003; Evans e Greeen, 2005), conforme explicado na seção 2, e se ancora mais especificamente no modelo teórico da Gramática de Construções de Goldberg (1995, 2006, 2019), assumindo todas as unidades da língua como construções, ou seja, pareamentos de forma e significado. A passiva é entendida como uma construção de estrutura argumental (cf. Goldberg, 1995, 2006), ou seja, um padrão oracional em que uma forma sintática se encontra associada a um significado semântico/pragmático ${ }^{4}$. Em outras palavras, a passiva apresenta uma forma única, descrita sintaticamente pelo esquema [NP1 ser+Vpp (por NP2) $]^{5}$, e associada ao significado de passividade ou afetação (cf. Pinker, Lebeaux, and Frost, 1987; Pinker, 1989), conforme explicitado na próxima seção. Nesse contexto, os objetivos deste trabalho são analisar semanticamente os verbos que se compatibilizam com a construção passiva em português e explicitar o papel que tanto aspectos semânticos quanto pragmáticos desempenham na compatibilização. Como hipótese, assume-se que esses fatores funcionais, em consonância com os modelos teóricos baseados no uso, atuam como restrições graduais e de ordem coercitiva na compatibilização. Para verificar a hipótese e alcançar os objetivos propostos, são utilizados não apenas dados de intuição ${ }^{6}$, mas também dados

\footnotetext{
${ }^{3}$ Segundo Barddal (2008), são três as acepções básicas para produtividade de um padrão oracional ou unidade linguística: generalidade, que significa que o padrão tem ampla cobertura, é esquemático e pouco restrito; regularidade, que significa que o padrão é regrado, composicional e apresenta regularidade de ocorrência; e extensibilidade, que significa que o padrão tem o potencial de atrair novos itens e é desdobrável para novas funções.

4 Alguns trabalhos sobre construções de estrutura argumental em português são: em uma perspectiva descritiva, Ciríaco (2011, 2014, 2015, 2017, 2018), dentre outros autores; em uma perspectiva experimental, Santos, Ciríaco e Souza (2019) e Santos, Souza e Ciríaco (2019).

${ }^{5}$ Prefere-se manter a notação dos sintagmas em inglês por ser comum na literatura especializada, mesmo quando escrita em português.

${ }^{6} \mathrm{O}$ fato de a Linguística Baseada no Uso enfatizar a utilização de dados de corpus não exclui a possibilidade de também se utilizar a introspecção e dados de intuição na análise da língua. Como ressalta Talmy (2007),
} 
anotados do uso escrito real, provenientes de sites de notícias brasileiros, seguindo os pressupostos da Linguística Baseada no Uso. Por fim, a intenção deste estudo, ao se trabalhar inicialmente com dados de intuição e de uso real, é possibilitar a construção de um conjunto de hipóteses norteadoras do planejamento experimental para pesquisas futuras, tendo em vista que a aplicação de experimentos psicolinguísticos constitui o passo seguinte no estudo da compatibilização semântica como capacidade cognitiva. $\mathrm{O}$ artigo está organizado da seguinte maneira: na seção 2, são explicitadas as noções teóricas e as opções metodológicas adotadas; na seção 3, analisa-se a compatibilização de diversas classes de verbos com a construção passiva em português e, na seção 4, são tecidas algumas considerações finais.

\section{REFERENCIAL TEÓRICO E METODOLOGIA DE ANÁLISE}

Segundo as teorias linguísticas baseadas no uso, o conhecimento linguístico do usuário emerge de sua experiência com a língua (de ouvir e falar). Como essa experiência vai se construindo a partir de padrões de uso mais ou menos rotineiros ou frequentes, as representações desse conhecimento se organizam de maneira gradiente na cognição humana, dando origem a estruturas gramaticais que refletem essa organização conceitual. Assim, em hipótese, as compatibilidades que podem ser observadas entre verbos e construções de estrutura argumental também se organizam de maneira gradual, refletindo uma escala de harmonização semântica em que algumas compatibilidades serão mais harmônicas e outras, menos. Isso significa que as restrições e funções relativas ao significado da construção passiva provavelmente não atuam de forma categórica, mas sim contínua.

De acordo com a Gramática de Construções de Goldberg, "qualquer padrão linguístico é reconhecido como uma construção desde que algum aspecto de sua forma ou função não seja estritamente previsível de suas partes componentes ou de outras construções já existentes" (Goldberg, 2006:5). Além disso, padrões linguísticos também podem ser armazenados como construções mesmo quando são totalmente previsíveis, desde que ocorram com frequência suficiente. Sendo assim, a passiva é uma construção porque é uma associação entre uma determinada forma sintática, que em português é [NP1 ser+Vpp (por NP2)], e aspectos funcionais de significação específicos, a serem checados neste artigo para o português.

Pinker et al (1987) propõem uma "Restrição de Afetação" (cf. Ambridge et al, 2016) para a construção passiva em inglês, segundo a qual a passiva é restrita a verbos que denotem ações ${ }^{7}$ e eventos de modo que o argumento mapeado na posição de sujeito da passiva está em um estado ou circunstância caracterizado pelo fato de que o argumento mapeado na posição de objeto da preposição 'por' (ou subentendido) agiu sobre ele. Em outras palavras, verbos se compatibilizam com a construção passiva quando o participante que será mapeado na posição de sujeito pode ser construído cognitivamente como um paciente, seja ele um paciente literal ou uma extensão abstrata do sentido prototípico dessa função semântica. Portanto, parte-se da premissa de que a construção passiva em

\footnotetext{
o uso de corpus e dados de frequência de uso não suprime o pensamento analítico, que é introspectivo por natureza. Portanto, uma análise que combina ambas as metodologias (intuição e uso) só pode apresentar vantagens.

${ }^{7}$ Em termos gerais, uma ação é o direcionamento de energia efetuado pelo agente a um paciente. O agente é, prototipicamente, aquele que age com intenção; e o paciente é, prototipicamente, aquele que sofre o efeito de uma ação.
} 
português também está associada ao significado mais geral de Afetação ${ }^{8}$ observado por Pinker e colegas. Shibatani $(1985,2006)$, por sua vez, propõe que a função primária da passiva em inglês e muitas outras línguas é a de desfocalização do agente, seja reservando ao agente uma posição sintática menos proeminente (objeto da preposição), seja omitindo-o completamente. Sendo assim, é preciso haver um agente para que a construção passiva seja uma alternativa viável para o usuário da língua. Desse modo, segundo Shibatani, a passiva não se aplica a verbos intransitivos não agentivos (os verbos inacusativos), mesmo em línguas em que a compatibilização de verbos intransitivos com a passiva é permitida. A passiva também não se compatibiliza com verbos transitivos cujo sujeito não é um agente prototípico ou periférico - segundo o autor, mesmo com a passiva tendo sido estendida para instâncias em que o sujeito é experienciador e não agente, como é caso de 'Mary is loved by John', a noção de agentividade como categoria radial ainda é crucial. Para o português, Furtado da Cunha (2000) observa algo semelhante, afirmando que passivas envolvem um agente pressuposto, que é parte do conhecimento pragmático geral ou identificável no contexto discursivo. Shibatani ainda realça que a conceptualização associada à passiva é a de um evento transitivo, afirmando que passivas prototípicas são semanticamente transitivas. Sobre esse aspecto, tanto Rice (1987a, b) para o inglês quanto Furtado da Cunha (1996) para o português mostram que a construção passiva está associada a aspectos do protótipo de transitividade (cf. Hopper e Thompson, 1980). Com base nesses estudos, será verificado qual é o papel de cada um desses aspectos funcionais - o significado de afetação e a função de desfocalização do agente - na compatibilização entre verbo e construção passiva em português.

Do ponto de vista da representação, uma construção é um agrupamento (cluster, no original) de traços falhos (lossy, no original) de memória que se alinham em nosso espaço conceitual com base no compartilhamento de forma, função e dimensões contextuais (Goldberg, 2019). Assim, tanto a representação da construção passiva quanto suas restrições de compatibilização emergem com base em aspectos funcionais compartilhados entre as várias instâncias de uso que os usuários da língua experienciam. Essas representações não são uniformes, mas estão sujeitas a alterações e extensões de seu significado, e até a restrições de tipo coercitivo, caso em que os usuários da língua recorrem ao mecanismo de coerção para interpretarem as expressões da língua ${ }^{9}$. Em geral, a coerção acontece quando é necessário um ajuste interpretativo diante de um conflito semântico entre o sentido normalmente associado a uma palavra e o sentido do padrão oracional em que ela ocorre (Michaelis, 2004). Um exemplo de coerção ocorre quando a expressão adverbial 'de repente', cujo sentido evoca prototipicamente um evento pontual como 'chegar', é combinada com um verbo mais associado a um sentido estativo como 'saber' em sentenças como 'de repente, ele soube tudo'. Nesse caso, segundo Michaelis, os usuários da língua concordam com um ajuste no sentido do verbo, que passa a significar algo como 'passar a saber'. O significado da construção passiva parece envolver esse recurso interpretativo de coerção, mas um de natureza pragmática, em que um construal cognitivo ou um cenário convencionalizado, ou seja, um contexto situacional com propriedades semânticas ou pragmáticas específicas, é responsável por forçar a harmonização entre verbo e construção de estrutura argumental. Neste trabalho, são mostrados os casos em que essa coerção ocorre ${ }^{10}$.

Para proceder à análise do papel desses fatores funcionais na compatibilização entre verbos e construção passiva, será adotada como metodologia a análise do grau de

\footnotetext{
${ }^{8}$ Neste trabalho, entende-se Afetação em termos gerais, como uma propriedade do argumento para o qual uma ação ou processo são direcionados.

${ }^{9}$ Ver também Croft (2001), Croft e Cruse (2004), Kemmer (2008), Boas (2011).

${ }^{10}$ Para mais casos de coerção em construções de estrutura argumental, consulte-se Ciríaco (2020).
} 
aceitabilidade, via intuição, de diversas classes de verbos do português (cf. CIRÍACO, 2011, 2014) na construção passiva, seja com dados construídos para este artigo, retirados do corpus compilado por Ciríaco (2011), ou com dados do uso real escrito, anotados de sites de notícias brasileiros. As classes verbais analisadas pertencem a quatro grandes grupos de verbos do português: verbos de ação (agentivos de afetação, verbos agentivos benefactivos, verbos agentivos de criação, verbos agentivos de mudança de lugar, verbos agentivos de locatum $^{11}$ ), verbos de causação (verbos causativo/agentivos e estritamente causativos), verbos de processo (verbos de obtenção, verbos de experiência) e verbos de estado (estado puro), conforme a divisão em classes feita em Ciríaco (2011). Vale realçar que essa divisão em classes é apenas uma referência para a análise, e que as minúcias de classificação lexical ${ }^{12}$, como a gramatura das classes e o sentido exato dos verbos, não importam para esta pesquisa nem tampouco para análises construcionistas em geral $^{13}$.

\section{A CONSTRUÇÃO DE ESTRUTURA ARgUMENTAL PASSIVA EM PORTUGUÊS}

\subsection{O Significado da Construção Passiva}

O significado da construção passiva em português também parece envolver o sentido geral de Afetação e a função de Desfocalização do Agente. Esses dois aspectos juntos individualizam a passiva - tanto o sentido de afetação quanto a função de desfocalização do agente podem estar associados a outras construções, mas apenas a passiva veicula esses dois aspectos juntos através da forma [NP1 ser+Vpp (por NP2)] em português $^{14}$ - e implicam duas hipóteses complementares: i) a compatibilização entre verbo e construção passiva será tão mais satisfatória quanto mais o sentido veiculado pela forma verbal de particípio estiver associado a um sentido de afetação ${ }^{15}$; e ii) a compatibilização entre verbo e construção passiva será tão mais satisfatória quanto mais agentiva for a conceptualização do evento descrito, o que depende de fatores contextuais. Como o objetivo deste trabalho é analisar a compatibilização semântica entre verbo e construção passiva, a restrição de afetação, que é o aspecto que mais se refere à harmonização entre o sentido do verbo e o sentido da construção, será analisada primeiramente. Posteriormente, será analisada a função de desfocalização do agente, que, apesar de ser um aspecto importante do significado da construção, parece ser uma restrição que atua apenas quando a restrição de afetação falha. Essa segunda restrição é de tipo coercitivo e de natureza contextual, como será mostrado mais adiante.

A hipótese da restrição de afetação se confirma para uma grande parte dos dados analisados em português (cf. metodologia descrita na seção 2). Verbos usualmente associados ao significado de ação/causação se harmonizam prontamente com a construção, seja seu significado agentivo ou causativo. Dentre os verbos tidos como

\footnotetext{
${ }^{11}$ Seguindo descrição de Clark e Clark (1979) e Hale e Keyser (2002), verbos de locatum são do tipo de 'amanteigar', que se conformam às paráfrases 'colocar manteiga em Y' ou 'prover y com manteiga'.

${ }^{12}$ Lembrando que do ponto de vista da Gramática de Construções, não faz nenhum sentido falar em "léxico" em sua acepção tradicional.

${ }^{13}$ Assume-se que esses aspectos de sentido são sujeitos a variação.

${ }^{14}$ A construção ergativa, por exemplo, também veicula o sentido de afetação - ou mais especificamente, o de mudança de estado - e também serve à função de desfocalização do agente. No entanto, esses aspectos de significado estão associados a outra forma sintática - a saber NP (se) V (ver Ciríaco, 2017).

15 Obviamente, essa associação do significado de afetação ao sentido da forma verbal depende de seu uso. Uma análise da frequência de uso das formas verbais poderia ser elucidativa e faz parte da agenda de pesquisa futura.
} 
agentivos, há aqueles que exprimem uma afetação específica a cada caso, como mostram os verbos das orações passivas ilustradas em (5)-(7) - ou seja: ficar junto, afinado ou com um corte; uma afetação do tipo de benefício, como mostram os exemplos em (8)-(10); uma afetação do tipo de criação, como mostram as orações em (11)-(13); uma afetação que exprime uma mudança de lugar, como mostram (14)-(16); ou uma afetação que exprime uma mudança do tipo locatum (ver nota 5), como mostram (17)-(19):

(5) Os brinquedos foram juntados pelas crianças.

(6) O violão foi afinado por José.

(7) A carne foi cortada por Maria.

(8) Paulo foi absolvido pelo juiz.

(9) Ana foi acolhida pela mãe.

(10) O vizinho foi acudido pelos bombeiros.

(11) A música foi composta por Marisa Monte.

(12) A tese foi escrita por Ana.

(13) Esse carro foi fabricado pelos italianos.

(14) Os documentos foram arquivados pelo estagiário.

(15) O dinheiro foi embolsado pelo policial corrupto.

(16) Os quadros foram emoldurados por um amigo meu.

(17) O ladrão foi algemado pela polícia.

(18) O menino foi agasalhado pela professora.

(19) O cavalo foi selado pelo funcionário.

Verbos causativos também estão associados a uma afetação, neste caso, do tipo mudança de estado. Eles também se harmonizam com o significado da construção passiva, seja a afetação uma mudança de estado físico, como mostram 'quebrar', 'abrir' e 'fechar' em (20)-(22), ou uma mudança de estado psicológico, como mostram 'acalmar', 'alegrar' e 'assustar' em (23)-(25):

(20) O vaso foi quebrado por João.

(21) A janela foi aberta por Bernardo.

(22) O registro foi fechado pelo síndico.

(23) Ana foi acalmada pela colega.

(24) A menina foi alegrada pelos palhaços.

(25) Antônio foi assustado pelo cachorro.

Entretanto, a restrição de afetação falha em explicar a compatibilização de alguns grupos de verbos. Por exemplo, verbos do tipo de 'amar', 'respeitar', 'cobiçar', 'invejar' e 'odiar' descrevem uma experiência e não estão associados a um sentido de afetação: seus papéis participantes são um experienciador e um alvo para o qual a experiência é direcionada. No entanto, o alvo da experiência não é necessariamente afetado por ela. Ainda assim, eles são compatíveis com a construção passiva:

(26) Ana foi amada por João.

(27) O professor foi respeitado pelos alunos.

(28) Esse sapato foi cobiçado por todas as mulheres.

(29) As atrizes foram invejadas por todos do estúdio.

(30) O assassino foi odiado por toda a comunidade. 
Da mesma maneira, verbos usualmente associados ao significado de obtenção (cf. Levin, 1983), cujos papéis participantes são um agente e um objeto adquirido, e, portanto, não envolvem um participante afetado, também se compatibilizam com a construção passiva:

(32) Esses bens foram acumulados por meu pai.

(32) Esse carro foi adquirido por meu pai.

(33) A vaga de emprego foi conseguida pelo profissional mais qualificado.

(34) Os documentos foram obtidos pelo despachante.

(35) Meus documentos foram reavidos pelo despachante.

O verbo 'ganhar', também pertencente ao grupo dos verbos de obtenção, apresenta uma particularidade: ora a restrição de afetação funciona, e sua compatibilização com a construção passiva não é licenciada - como mostram '?O presente foi ganho pela criança' ou '?A homenagem foi ganha pela professora' -, ora a restrição de afetação não funciona e, assim como os demais verbos de obtenção, apesar de não estar associado ao sentido de afetação, 'ganhar' se compatibiliza com a construção passiva, como mostram os dados de sites de notícias a seguir:

(36) "acredito que a parte da batalha liderada por cientistas engajados e conectados para reverter essa atrocidade foi ganha porque ser contra a ciência e os cientistas se tornou socialmente inaceitável em 2020.” (https://jornal.usp.br/artigos/2020-um-teste-deresiliencia-e-um-ano-de-reinvencao/)

(37) "Se ação foi ganha depois da concessão da aposentadoria, o aposentado pode pedir que o processo seja incluído no cálculo do seu benefício." (https://www.mixvale.com.br/2021/01/01/fique-atento-aprenda-a-diferenciar-revisoesde-golpes-no-inss/)

(38) "A taça foi ganha com o empate por 1 a 1 com o Chile." (https://www.mg.superesportes.com.br/app/noticias/futebol/futebolinternacional/2020/12/18/noticia_futebol_internacional,3879204/selecao-sub-20empata-com-o-chile-e-conquista-torneio-na-granja-comary.shtml)

(39) "Diante de um ano letivo cujos efeitos serão sentidos por décadas na educação brasileira, a BBC News Brasil conversou com educadores, alunos e especialistas do setor para saber: o que foi perdido e o que foi ganho na educação em 2020?" (https://educacao.uol.com.br/noticias/bbc/2020/12/30/educacao-em-2020surpreendentes-legados-positivos-em-ano-quase-perdido.htm)

(40) "O projeto que você se refere foi ganho em uma tomada de preços pública e nós tivemos o menor preço, muito inferior ao que seria cobrado a um cliente privado" (https://www.brasildefato.com.br/2020/12/29/apos-denuncia-do-brasil-de-fato-edital-decultura-do-governo-doria-e-cancelado)

O que os dados em (26)-(40) mostram é o seguinte: embora nenhum desses verbos atendam à restrição de afetação ${ }^{16}$, todos pressupõem um agente ou traços de agentividade

\footnotetext{
${ }^{16}$ Não se pode dizer que 'Ana' é afetada em (26) pelo amor de João, ela é apenas o objeto da experiência dele. Do mesmo modo, não se pode dizer que 'esses bens' em (32) ou que 'a ação' e 'a taça' em (37) e (38) são afetados, e assim extensivamente a todos os dados mostrados em (26)-(40).
} 
para o evento descrito quando instanciam a construção passiva: em (26), pressupõe-se que houve intenção de João em amar Maria; em (32), pressupõe-se a intenção do pai em acumular bens; em (37), a batalha foi ganha por aqueles que a lideraram e, consequentemente, agiram propositadamente para tal; em (37), a ação foi ganha após o investimento e iniciativa de alguém; em (38), a taça foi ganha após um evento de ação, que foi o jogo; em (39), as passivas 'foi perdido' e 'foi ganho' se encontram em um contexto de dificuldade, em que foi preciso esforço e adaptação por parte de educadores, alunos e especialistas, sendo conceptualizados como participantes ativos diante desse contexto; em (40), o contexto em que o projeto 'foi ganho' é o de uma licitação pública, em que vários participantes competem e disputam pelo licenciamento.

Portanto, o significado da construção passiva envolve não apenas o significado de afetação, mas também uma conceptualização agentiva do evento. Assim, se um verbo não apresenta o significado de afetação, mas pode ser conceptualizado como um evento agentivo ou com traços de agentividade, pressupondo um tipo de agente seja no sentido prototípico ou periférico, então a compatibilização é possível. Nesses casos, o evento denotado pelo verbo passa por um ajuste interpretativo que faz com que o participante que não estava associado ao sentido de afetação passe a ser interpretado como afetado no caso dos verbos de experiência, é o alvo da experiência que passa a ser interpretado como afetado, e no caso dos verbos de obtenção, é o objeto obtido. Em outras palavras, trata-se de uma coerção: uma conformação do sentido do verbo ao sentido da construção a fim de licenciar sua compatibilização.

O mecanismo coercitivo da construção passiva está intimamente relacionado à função de desfocalização do agente: se um evento passa a ser conceptualizado como agentivo ou pressupondo um tipo de agente, então há agente a ser desfocalizado na estrutura formal da construção - sendo omitido ou aparecendo na posição pouco proeminente de objeto da preposição 'por'. Assim, pode-se dizer que a função de desfocalização do agente motiva o ajuste interpretativo da coerção. Além disso, a coerção estabelece um cenário convencionalizado para a compatibilização, qual seja, um contexto mais ou menos implícito de ação.

Outros sentidos verbais, como aqueles associados a eventos puramente estativos e relacionais não se compatibilizam com a construção passiva por não atenderem à restrição de afetação nem tampouco à função de desfocalização do agente:

(41) *A fazenda era beirada pela estrada.

(42) *O palhaço era parecido por ele.

(43) *Azul era significado pela palavra blue.

(44) *Uma casa foi tida por Francisco.

(45) *Cem reais foram custados pelo livro.

(46) * Muito dinheiro foi valido por esse carro.

Por outro lado, alguns desses verbos podem estar associados a dois sentidos distintos: um relacional e estativo, e outro agentivo. Nesse último caso, o verbo atende tanto à restrição de afetação quando à função de desfocalização do agente, não sendo necessário um ajuste coercitivo ${ }^{17}$ :

\footnotetext{
17 Os verbos 'anteceder', 'suceder' e 'preceder' são contraexemplos. No entanto, as construções passivas formadas com eles exigem a presença do [SPpor], o que não é uma característica prototípica da construção passiva e merece uma investigação à parte (cf. O homicídio foi antecedido pelo assalto. / ??o homicídio foi antecedido; Carlos foi precedido pelo pai./ ??o pai foi precedido; FHC foi sucedido por Lula. / ??FHC foi sucedido).
} 
(47) *A área foi possuída pelo fazendeiro. / O homem foi possuído por forças ocultas.

(48) $* 3 \mathrm{~km}$ foram medidos por essa rua. / A sala foi medida pela arquiteta.

(49) $* 2 \mathrm{~kg}$ foram pesados por esse peixe. / A carne foi pesada pelo açougueiro.

(50) *4 mesas são contidas por essa sala. / A invasão foi contida pela polícia.

Por fim, há uma classe de verbos estritamente causativos, como 'preocupar' (CIRÍACO, 2011), que atendem à restrição de afetação e podem ser conceptualizados como agentivos no sentido mais periférico da categoria ${ }^{18}$ (ver LANGACKER, 2008), como mostra (51). Entretanto, não se compatibilizam com a construção passiva (52):

(51) "Mike Perry preocupa seguidores ao postar video ensangüentado e mensagem misteriosa" (https://www.uol.com.br/esporte/ultimas-noticias/ag-fight/2021/01/04/mikeperry-preocupa-seguidores-ao-postar-video-ensanguentado-e-mensagemmisteriosa.htm).

(52) *Seguidores foram preocupados por Mike Perry.

A hipótese formulada para explicar esse fato, ainda a ser checada, é a de que a construção ilustrada em (53) e (54) - um tipo de construção com a preposição "com", sem a possibilidade de agente da passiva, mas relacionada semanticamente com a construção passiva prototípica - é mais frequente com esses verbos e, por isso, bloqueia a ocorrência da passiva prototípica:

(53) “A polícia é orientada, é treinada para entregar o infrator preso. A polícia sempre foi preocupada com isso. O confronto não é algo desejável, porque também é um risco para o policial” (https://www1.folha.uol.com.br/cotidiano/2020/01/homicidios-dolosos-caemem-sp-mas-mortes-por-policiais-tem-alta.shtml)

(54) "Mas, reconheçamos a voz da arquibancada nunca foi preocupada com educação." (https://www.uol.com.br/esporte/futebol/ultimas-noticias/2020/01/31/time-deassassinos-qual-e-o-limite-do-torcedor-blogueiros-opinam.htm)

Como resumo da análise da compatibilização entre o significado dos verbos e o significado da construção passiva em português, a tabela a seguir mostra, de maneira esquemática, a emergência do sentido de afetação que foi verificado ao longo da análise empreendida nesta seção do artigo, confirmando a hipótese de trabalho. Complementarmente à restrição de afetação, a construção passiva em português dispõe de um mecanismo de coerção de natureza semântico-pragmática que, dado um cenário convencionalizado específico (de ação), efetua um ajuste interpretativo - fazendo um participante não afetado ser interpretado como afetado - que torna possível a compatibilização entre verbo e construção.

\footnotetext{
${ }^{18} \mathrm{Na}$ abordagem cognitiva, uma causa, dentre outras funções semânticas, estaria na periferia da categoria agente.
} 
Tabela 1 - Sentido que emerge das classes de verbos compatíveis com a construção passiva.

\begin{tabular}{|c|c|c|c|}
\hline $\begin{array}{l}\text { Classes de verbos } \\
\text { transitivos }\end{array}$ & Exemplos esquemáticos & $\begin{array}{c}\text { Sentido emergente } \\
\text { das classes }\end{array}$ & $\begin{array}{l}\text { Sentido emergente de } \\
\text { todas as classes }\end{array}$ \\
\hline Agentivos de afetação & $X$ foi cortado por $Y$ & \multirow{5}{*}{$\mathrm{X}$ foi afetado por $\mathrm{Y}$} & \multirow{8}{*}{$\mathrm{X}$ foi afetado por $\mathrm{Y}$} \\
\hline Agentivos benefactivos & $X$ foi ajudado por $Y$ & & \\
\hline Agentivos de criação & $\mathrm{X}$ foi construído por $\mathrm{Y}$ & & \\
\hline $\begin{array}{l}\text { Agentivos de mudança } \\
\text { de lugar }\end{array}$ & $\mathrm{X}$ foi arquivado por $\mathrm{Y}$ & & \\
\hline $\begin{array}{l}\text { Agentivos de mudança } \\
\text { de posse }\end{array}$ & $\mathrm{X}$ foi algemado por $\mathrm{Y}$ & & \\
\hline $\begin{array}{l}\text { Causativo/ agentivos (ou } \\
\text { verbos causativos de } \\
\text { mudança de estado) }\end{array}$ & $\begin{array}{l}X \text { foi quebrado por } Y \\
X \text { foi assutado por } Y\end{array}$ & $\mathrm{X}$ foi afetado por $\mathrm{Y}$ & \\
\hline De obtenção & $\begin{array}{l}\mathrm{X} \text { foi ganho por Y, em } \\
\text { cenário específico }\end{array}$ & $\begin{array}{l}\mathrm{X} \text { foi afetado por Y, } \\
\text { em cenário } \\
\text { específico }\end{array}$ & \\
\hline De experiência & $\begin{array}{l}\mathrm{X} \text { foi admirado por Y, } \\
\text { em cenário específico }\end{array}$ & $\begin{array}{l}\mathrm{X} \text { foi afetado por } \mathrm{Y}, \\
\text { em cenário }\end{array}$ & \\
\hline
\end{tabular}

\subsection{O Padrão Oracional da Passiva}

As informações sobre forma e significado da construção passiva em português podem ser esquematizadas no seguinte padrão oracional:

\section{(55) Construção Passiva}

FORMA SINTÁTICA:

$\left[\mathrm{NP}_{1}\right.$ ser+Vpp (por $\left.\left.\mathrm{NP}_{2}\right)\right]$

\section{SIGNIFICADO SEMÂNTICO-PRAGMÁTICO:}

Sentido: $\mathrm{X}_{1}$ É AFETADO por $\mathrm{Y}_{2}$

Cenário convencionalizado: Ação

Função: Desfocalização do Agente

RESULTADO: $\mathrm{X}_{1}$ é afetado.

Os participantes $\mathrm{X}_{1}$ e $\mathrm{Y}_{2}$ são mapeados nas posições $\mathrm{NP}_{1}$ e $\mathrm{NP}_{2}$ respectivamente, como indicam os índices. $\mathrm{O}$ sintagma (por $\mathrm{NP}_{2}$ ) é notado entre parênteses a fim de indicar sua opcionalidade. Há três tipos de restrições para haver compatibilização com os verbos: i) o sentido da construção, que equivale à restrição de afetação; ii) o cenário convencionalizado de ação, que pode ser atendido por meio de um ajuste na interpretação do participante X; e iii) a função de desfocalização do agente, que atende a uma necessidade semântico-discursiva e se manifesta sintaticamente. Por fim, é preciso realçar que a análise proposta para a construção passiva engloba todas as suas elaborações na língua, incluindo-se aquelas instâncias que não apresentam ativa correspondente (como mostrado em (2)). 


\section{CONSIDERAÇÕES FINAIS}

Neste trabalho, tanto a Restrição de Afetação quanto a Função de Desfocalização do Agente observadas em diversos estudos sobre a construção passiva em inglês, português e outras línguas foram desmembradas em hipóteses de trabalho. Iniciou-se com a verificação da efetividade da restrição de afetação na compatibilização de diversas classes de verbos do português na construção passiva. A análise dos dados mostrou que o significado da passiva também envolve o cenário convencionalizado de ação, que atua como uma restrição coercitiva, ajustando a interpretação de afetação quando possível e estendendo a cobertura da construção passiva na língua. Tanto a restrição de afetação quando o cenário convencionalizado de ação servem à função de desfocalização do agente. Por fim, uma representação da construção passiva em português foi proposta, de forma a mostrar todas as informações descobertas na análise de maneira esquemática e resumida.

Em conclusão, este trabalho mostra a existência de restrições funcionais para a compatibilização entre verbo e construção passiva em português, explicitando o papel desses fatores. Como próximo passo, vislumbra-se a necessidade de um estudo experimental para o português, por meio de testes gradientes de aceitabilidade intraconstrução ${ }^{19}$, ranqueamentos de semântica verbal e coleta de tempos de reação em experimentos cronométricos, à semelhança de Ambridge et al (2016), a fim de se atestar a realidade psicológica das restrições investigadas neste trabalho e as condições em que são observadas pelos usuários da língua. Esse será um estudo a ser conduzido futuramente.

\section{REFERÊNCIAS}

AMBRIDGE, Ben; BIDGOOD, Amy; PINE, Julian M.; ROWLAND, Caroline F.; FREUDENTHAL, Daniel. Is Passive Syntax Semantically Constrained? Evidence From Adult Grammaticality Judgment and Comprehension Studies. CognSci. 2016 Aug; 40(6): 1435-1459.

BARDDAL, Jóhanna. The role of thematic roles in constructions? Evidence from Icelandic inchoative. Proceedings of the 18th Scandinavian Conference of Linguistics, vol. 1, p. 127- 137. 2001.

BARLOW, Michael; KEMMER, Suzanne. Usage-based models of Language. CSLI Publications, 2000.

BOAS, H. C. Coercion and leaking argument structures in Construction Grammar. Linguistics 49-6, 2011. p. 1271-1303.

CIRÍACO, Larissa. A hipótese do contínuo entre o léxico e a gramática e as construções incoativa, medial e passiva do PB. Tese de doutorado. UFMG, 2011.

CIRÍACO, Larissa. A construção transitiva no PB: associando a gramática de construções à decomposição semântica de predicados. Alfa Revista de Linguística. 2014.

CIRÍACO, Larissa. A construção transitiva de sujeito agente-beneficiário no português brasileiro. Caligrama, v. 19, n. 2, 2015.

CIRÍACO, Larissa. A família de construções ergativas no português. PERcursos Linguísticos, v. 7, n. 14, p. 421-435, 2017.

CIRÍACO, Larissa. Construções de estrutura argumental recíprocas em português. Actas do XIII CILX. Disponível em: <http://cilx2018.uvigo.gal/actas/>, 2018.

CIRÍACO, Larissa. A coerção aspectual em construções de estrutura argumental: um projeto de pesquisa na área da Psicolinguística Experimental. In: Oliveira, C. S. F.; Sá, T. M. (orgs) Psicoliguística em Minas Gerais, Cefet, 2020.

\footnotetext{
${ }^{19}$ Guimarães (2021) não encontrou diferenças entre os julgamentos de gramaticalidade entre construções passivas e transitivas, no entanto, não havia um entendimento dos fatores funcionais de compatibilização entre verbo e construção passiva como o delineado aqui. De fato, é de se esperar que a comparação entre passivas e transitivas não mostre diferenças nem seja a comparação relevante, tendo em vista que ambas pertencem ao mesmo contexto funcional - um cenário convencionalizado e prototípico de ação -, como mostram os resultados discutidos neste artigo.
} 
CLARK, Eve V.; CLARK, Herbert H. When nouns surface as verbs. Language, 55, 767-811. 1979. Reprinted in: F. Katamba (Ed.), Critical concepts in linguistics, vol. 5: Morphology: its relation to semantics and the lexicon. London: Routledge, 2003. Pp. 128-183.

CHOMSKY, Noam. A minimalist program for linguistic theory. In Hale K. \& Keyser S. J. (Eds.), The view from building 20 (pp. 1-52). Cambridge, MA: MIT Press, 1993.

CHOMSKY, Noam. The minimalist program. Cambridge, Mass.: MIT Press. 1995.

CROFT, William. Radical Construction Grammar: syntactic theory in typological perspective. Oxford: Oxford University Press, 2001.

CROFT, William e CRUSE, D. Alan. Cognitive linguistics. Cambridge: Cambridge University Press, 2004.

EVANS, Vyvyan; GREEN, Melanie. Cognitive Linguistics: an introduction. Mahwah, NJ: Lawrence Erlbaum Associates, 2005.

FURTADO DA CUNHA, Maria Angélica. Transitividade e passiva. Revista de Estudos da Linguagem, Belo Horizonte, v. 1, n. 4, p. 46-61, 1996.

FURTADO DA CUNHA, Maria Angélica. A complexidade da passiva e as implicações pedagógicas do seu uso. Linguagem \& Ensino, vol. 3, n. 1, p. 107-116, 2000.

GOLDBERG, Adele. Constructions: A construction grammar approach to argument structure.Chicago, IL: University of Chicago Press, 1995.

GOLDBERG, Adele. Constructions at work: the nature of generalization in language. Oxford: Oxford University Press, 2006.

GOLDBERG, Adele. Explain me this: creativity, competition, and the partial productivity of constructions. Princeton: Princeton University Press, 2019.

GUIMARÃES, Mara. Frequency effects of L2 English on the processing of the passive in L1 Brazilian Portuguese. Revista de Estudos da Linguagem, Belo Horizonte, v. 29, n. 1, p. 215-258, 2021.

HALE, Kenneth e KEYSER, Samuel. Prolegomenon to a Theory of Argument Structure. Cambridge: MIT Press, 2002.

HOPPER, Paul J.; THOMPSON, Sandra A. Transitivity in grammar and discourse. Language, v. 56 (2), p. 251-299, 1980.

KEMMER, Suzanne. New dimensions of dimensions: Frequency, productivity, domains and coercion. Paper presented at the meeting of Cognitive Linguistics between Universality and Variation, Dubrovnik, Croatia, 2008.

LANGACKER, Ronald. Foundations of cognitive grammar. Volume I. Stanford: Stanford University Press, 1987.

LANGACKER, Ronald. Concept, Image and Symbol: The Cognitive Basis of Grammar. Mouton de Gruyter, 1990.

LANGACKER, Ronald. Foundations of Cognitive Grammar. Volume II, Descriptive Application. Stanford, California: Stanford University Press, 1991.

LANGACKER, Ronald. Cognitive Grammar: a basic introduction. Oxford: Oxford University Press, 2008.

LEVIN, Beth. English verb classes and alternations. Chicago: The University of Chicago Press, 1993.

MICHAELIS, Laura A. Type Shifting in Construction Grammar: An Integrated Approach to Aspectual Coercion. Cognitive Linguistics 15: 1-67, 2004.

PERINI, Mário A. Los dos participios y el análisis de las pasivas en el portugués de Brasil. Manuscrito. UFMG. 2010.

PERINI, Mário A. Describing Verb Valency: Practical and theoretical issues. Cham, Swtizerland: Springer International Publishing AG, 2015.

PERINI, Mário A. Thematic Relations: A Study in the Grammar-Cognition Interface. Cham, Swtizerland: Springer International Publishing AG, 2019.

PINKER, Steven; LEBEAUX, David S.; FROST, Loren A. Productivity and constraints in the acquisition of the passive. Cognition, 26 (1987) 195-267.

PINKER, Steven. Learnability and cognition: The acquisition of argument structure. Cambridge, MA; London: MIT, 2013 (primeira publicação em 1989).

RICE, Sally. Towards a Cognitive Model of Transitivity. Doctoral dissertation. San Diego: University of California, 1987a.

RICE, Sally. Transitivity and the Lexicon. Center for Research in Language, vol 2, n. 2, University of Califórnia, San Diego, LA. 1987b.

SANTOS, Clarice; SOUZA, Ricardo; CIRÍACO, Larissa. When Knowing a Grammar Rule makes L2 Users Non-Native Like. Ilha do Desterro v. 72, no 3, p. 359-374, Florianópolis, set/dez, 2019.

SANTOS, Clarice; CIRÍACO, Larissa; SOUZA, Ricardo. The Caused-Action Construction in Brazilian Portuguese (BrP) and its effect on the Comprehension and Production of BrP-English Bilingual Speakers. Diacrítica, Vol. 33, N. ${ }^{\circ}$ 2, 2019, 216-228. 2019. 
SHIBATANI, Masayoshi. Passives and Related Constructions: A Prototype Analysis. Language, 61.4, p. 821-848, 1985.

SHIBATANI, Masayoshi. On the conceptual framework for voice phenomena. Linguistics, 44(2):217-269, 2006.

TALMY, L. Foreword. In González-Márquez, Mónica et al., eds. 2007. Methods in cognitive linguistics. Amsterdam: John Benjamins. 2007.

TOMASELLO, Michael. Constructing a language. Boston: Harvard University Press, 2003.

Recebido: 20/1/2021

Aceito: 4/6/2021

Publicado: 27/8/2021 